\title{
Familial Clustering of Antiphospholipid Syndrome
}

\author{
Asma Saadia, Sana Haseeb Khan and Muhammad Dilawar Khan \\ Department of Pathology, Shalamar Medical and Dental College, Lahore, Pakistan
}

\begin{abstract}
Antiphospholipid syndrome (APS) is a systemic autoimmune disease characterised by thrombosis (venous or arterial) and/or pregnancy-related complications. There is very scanty literature available regarding familial occurrence of APS worldwide and to the best of our knowledge, this important aspect has never been previously reported from Pakistan. We are presenting three patients of a Pakistani family who presented with thrombotic and pregnancy-related complications. Screening of the asymptomatic family members was also carried out. Knowledge about the familial occurrence of the disease is important not only for better management of such patients but also to emphasise the need for future studies to unveil its genetic basis.
\end{abstract}

Key Words: Antiphospholipid syndrome, Familial, Thrombo embolism.

How to cite this article: Saadia A, Khan SH, Khan MD. Familial clustering of antiphospholipid syndrome. J Coll Physicians Surg Pak 2019; 29(12):1221-1224.

\section{INTRODUCTION}

Antiphospholipid syndrome (APS) is a systemic autoimmune disease characterised by thrombosis (venous or arterial) and/or pregnancy-related complications. It is associated with the presence of certain antibodies [lupus anticoagulant ( $\mathrm{LAC}$ ), anticardiolipin ( $\mathrm{aCL}$ ) antibodies, or anti- $\beta 2$-glycoprotein I (anti- $\beta 2 \mathrm{GPI}$ ) antibodies]. ${ }^{1}$ Their mechanism of action is heterogeneous. Though, the pathogenic role of these antibodies is widely accepted, the fact that the antibody-induced thrombosis occurs only occasionally, suggests some "environmental hit" to unveil its clinical manifestations. ${ }^{2}$ The patients are diagnosed with the help of Sapporo criteria. ${ }^{1}$ There should be at least one laboratory and one clinical feature present for the diagnosis.

Annual incidence of APS is about 2 persons per 100,000 per year, affecting both sexes equally and peaks at ages greater than 75 years. ${ }^{3}$ APS is called primary antiphospholipid syndrome (PAPS), when it occurs on its own; and secondary antiphospholipid syndrome (SAPS) when it occurs in association with some underlying autoimmune disease, e.g. systemic lupus erythematosus (SLE). It is a multi-factorial and polygenic disease caused by interaction of different genes which affect in combination with environmental factors. This makes it difficult to determine a person's risk of inheriting or passing on this disorder. ${ }^{4}$ Familial APS cases are rarely reported worldwide; and to the best of our knowledge, there is no case report on familial APS in Pakistan so far.

Correspondence to: Dr. Asma Saadia, Department of Pathology, Shalamar Medical and Dental College, Lahore, Pakistan

E-mail: asmasaadia@yahoo.com

Received: July 28, 2018; Revised: June 01, 2019

Accepted: June 01, 2019
In this report, we present three patients from the same family, who presented to us with recurrent thromboembolic episodes and pregnancy-related problems. Our report not only highlights the familial occurrence of the PAPS but also the gaps we faced in their therapeutic as well as prophylactic management. We have also addressed the screening of asymptomatic members of the family and the psychosocial issues they faced due to grave outcome of affected members.

\section{CASE REPORT}

Case 1: Case 1 presented for the first time in May 2008, at the age of 18 years with right leg pain for 20 days along with shortness of breath for 10 hours. He was extensively investigated, and was diagnosed to have deep venous thrombosis (DVT) with pulmonary embolism (PE). During his stay in the hospital, he was screened for thrombophilia that was negative. He was given streptokinase and discharged on warfarin (which he took for 6 months).

He suffered another episode of DVT in May 2010. After acute management with low molecular weight heparin (LMWH), he was advised to continue warfarin.

He presented with second episode of PE in May 2014, while he was still on warfarin. He was referred to us for the workup of repeated thrombosis despite on anticoagulation. Baseline investigations at that time showed platelet count of $70 \times 109 / \mathrm{L}$; prothrombin time (PT), 21 seconds (control $12 \mathrm{sec}$ ); international normalized ratio (INR), 1.8; and activated partial thromboplastin time (APTT), $43 \mathrm{sec}$ (control $33 \mathrm{sec}$ ). Due to younger-age patient with repeated thrombo-embolism, thrombocytopenia and prolonged APTT, we screened him for APS. Pertinent investigations are shown in Table I. Having made the diagnosis of APS with thrombocytopenia, the dose of warfarin was adjusted to maintain the 
Table I: Laboratory investigations of patients 1,2 and 3 at the time of presentation.

\begin{tabular}{|c|c|c|c|c|c|c|c|c|}
\hline Cases & Age (years) & $\begin{array}{l}\text { Platelet count } \\
\text { (normal } 150 \text { to } \\
450 \times 109 / \mathrm{L} \text { ) }\end{array}$ & $\begin{array}{c}\text { APTT } \\
\text { (control) }\end{array}$ & LAC & $\begin{array}{c}\mathrm{aCL}(\lg \mathrm{M})^{*} \\
\mathrm{U} / \mathrm{mL}\end{array}$ & $\begin{array}{c}\mathrm{aCL}(\lg G)^{*} \\
\mathrm{U} / \mathrm{mL}\end{array}$ & $\begin{array}{c}\text { ANA } \\
\text { (normal liters } \\
<1: 100)\end{array}$ & Anti-ds DNA* \\
\hline 1 & 18 & $70 \times 109 / \mathrm{L}$ & $43(32)$ & Positive & $14.626^{*}$ & $14.801^{*}$ & Negative & 5.6 \\
\hline 2 & 22 & $60 \times 109 / L$ & $45(30)$ & Positive & 78.1 & $>280$ & Negative & 12.1 \\
\hline 3 & 24 & $100 \times 109 / L$ & $32(29)$ & Positive & 66.7 & 280 & Negative & 1.50 \\
\hline
\end{tabular}

APTT: Activated partial thromboplastin time

LAC: Lupus anticoagulant; aCL : Anti cardiolipin antibodies; ANA: Anti nuclear antibodies; Anti-ds DNA: Anti double stranded DNA

*Interpretation of aCL (IgM \& IgG) levels of patient 1: Normal $<10(\mathrm{U} / \mathrm{ml}) ; \quad$ Elevated $\geq 10(\mathrm{U} / \mathrm{ml})$

This is a quantitative enzyme immunoassay intended to screen for the presence of lgM/lgG class of autoantibodies against cardiolipin, phosphatidyl serine, phosphatidyl inositol, phosphatidic acid and beta -2 -glycoprotein in human serum.

Anti ds-DNA (U/ml): Negative <20; Equivocal 20-25; Positive $\geq 25$

*Interpretation of results of patient 2 and 3 :

aCL IgM (units MPL U/mL): Negative <13.0; Equivocal 13.0-14.9; Low positive 15.0-39.9; Moderate positive: 40.0-79.9; High positive >80.0

aCL IgG (units GPL U/mL): Negative <20.0; Low positive 20.0-39.9; Moderate positive: 40.0 -79.9; High positive: >80.0

${ }^{*} \mathrm{aCl}$ (IgG and IgM) was performed on LIASON(DIASORIN) immunodiagnostics system using chemiluminescence technology.

Note: Difference in laboratory parameters, values/reference ranges between patient 1 and $2 / 3$ is due to tests being done at different laboratories using different technologies.

Table II: Laboratory investigations of asymptomatic family members.

\begin{tabular}{|c|c|c|c|c|c|c|}
\hline & $\begin{array}{c}\text { Age } \\
\text { (years) }\end{array}$ & $\begin{array}{c}\text { Platelet count } \\
\text { (normal } 150-450 \times 109 / L \text { ) }\end{array}$ & $\begin{array}{l}\text { APTT } \\
\text { (control) }\end{array}$ & LAC & $\begin{array}{c}\mathrm{aCL}(\lg \mathrm{M})^{*} \\
\mathrm{U} / \mathrm{ml}\end{array}$ & $\begin{array}{c}\mathrm{aCL}(\lg G) \# \\
\mathrm{U} / \mathrm{ml}\end{array}$ \\
\hline Father & 43 & $261 \times 109 / L$ & $33(33)$ & Negative & 3.1 & 4.2 \\
\hline Mother & 46 & $294 \times 109 / L$ & $34(33)$ & Negative & 4.1 & 3.2 \\
\hline Daughter & 20 & $178 \times 109 / L$ & $34(33)$ & Weak positive & 4.2 & 10.2 \\
\hline Son & 14 & $404 \times 109 / L$ & $34(33)$ & Negative & 4.1 & 3.1 \\
\hline
\end{tabular}

APTT: Activated partial thromboplastin time; LAC: Lupus anticoagulant; aCL : Anti cardiolipin antibodies.

*Interpretation of aCL lgM levels: Normal $<7(\mathrm{U} / \mathrm{ml})$; Elevated $\geq 7(\mathrm{U} / \mathrm{ml})$.

\# Interpretation of aCL lgG levels: Normal $<10(\mathrm{U} / \mathrm{ml})$; Elevated $\geq 10(\mathrm{U} / \mathrm{ml})$.

INR between 2 to 3 . After 5 months, he presented to emergency with heamoptysis and expired, most likely from another episode of PE or anticoagulant overdose.

Case 2: Case 2 [sister of case 1] was a 22-year female who was referred to us in November, 2015 at 6 weeks gestation. Past history was significant for miscarriage at 12 weeks of gestation, seven months back. Keeping the history of his brother in mind, she was advised antiphospholipid screening, the results of which are shown in Table I. Low molecular weight heparin (LMWH) and aspirin were started. Regular follow-ups with anti$\mathrm{Xa}$ assay were performed for monitoring LMWH. Serial complete blood counts (CBCs) showed falling trend of platelets. Her caesarean section was done at 32 weeks of gestation due to imminent eclampsia. Patient went into thrombotic thrombocytopenic purpura (TTP). This diagnosis was based on seizures, thrombocytopenia (platelet count $5 \times 109 / \mathrm{L}$ ), leucoerythroblastic picture with schistocytes on peripheral smear, lactate dehydrogenase (LDH), $1628 \mathrm{U} / \mathrm{ml}$ (normal upto $230 \mathrm{U} / \mathrm{ml}$ ) and negative Coomb's test. Despite multiple sessions of plasma exchange, she died. The male baby expired after 2 days due to severe biventricular dysfunction.

Case 3: Case 3 was a 24-year female (sister of case 1 and twin sister of case 2). In November 2017, she presented with DVT of left leg. She gave history of a pregnancy loss at seven weeks gestation one year back. She was given LMWH and warfarin. Her laboratory results are shown in Table I. She was advised lifelong anti-coagulation due to strong thrombotic history of her siblings.

Case 4: Younger sister of the affected patients, was a 21-year female who committed suicide due to grave outcomes of her siblings.
We screened other family members for APS after getting their written informed consent. Results of the family are given in Table II, which shows younger sister to have positive LAC.

\section{DISCUSSION}

We present the first ever case series of familial PAPS from Pakistan. All three cases were siblings (Table I) who experienced recurrent thrombo-embolic episodes and pregnancy-related complications. All patients had positive LAC and high titre aCL. Most data from previously published studies show that cases of APS belong to older age groups (mean age 40 years).2,5 However, Islam et al. ${ }^{4}$ reported the familial occurrence of APS in young population (mean age 26.3 years) which is in accordance with our study, in which the mean age is even younger (21.3 years). It shows that in familial cases expression of the disease can manifest at a younger age as compared to sporadic cases.

In patients with APS, there are multiple clinical and laboratory features in addition to those included in the diagnostic criteria. Most important amongst them is thrombocytopenia, which can be seen in $20-50 \%$ of APS patients. 6 All symptomatic cases in our study had moderate thrombocytopenia (Table I). This combination of thrombocytopenia with APS is referred to as 'hematological APS'. The pathogenesis of thrombocytopenia in APS patients is multifold and may include increased platelet activation and destruction, increased pooling and reduced production. Patients with reduced platelets are mostly at risk of development of thrombosis, especially those having high titre aCL. Clinically, 
significant bleeding mostly occurs when count falls below 10 to $20 \times 109 / \mathrm{L}$, usually in the setting of disseminated intravascular coagulation (DIC), TTP or catastrophic antiphospholipid syndrome (CAPS). Patients whose platelet counts are below 50×109/L may be candidates for additional therapeutic regimens that may include use of glucocorticoids and immunosupressive drugs as compared to APS patients with normal platelet counts. Thus, thrombocytopenia is an important finding in APS patients from management point of view. 6

Due to serious manifestations of the disease, we screened the asymptomatic family members for APS with platelet count, APTT, LAC, aCL (IgG and IgM) (Table II). After observing the overall laboratory results of the family, following points were raised in our minds that opened the doors to further research.

According to the established diagnostic criteria for APS, the positive laboratory results should be repeated on two occasions at least 12 weeks apart. ${ }^{1}$ This criterion should be relaxed for the familial cases in which family history is strong and the clinical expression is highly suggestive. As in our case, in which two of the family members had already died due to the complications of the disease, case 3 could be diagnosed on positive laboratory results on a single occasion rather than unnecessarily waiting for 12 weeks and repeating the tests, especially in the background of financial constraints.

According to previously published studies, multipositivity for antibodies is associated with increased risk of thrombotic complications as compared to a single positive test. Triple positive results $\mathrm{LAC}, \mathrm{aCL}$, and anti$\beta 2 \mathrm{GPI}$ antibodies are strongly linked with thrombosis. ${ }^{7}$ Screening results showed that the younger daughter of the family, who is 20 years old, had weak positivity for LAC. Keeping in view the very strong clinical manifestations of APS in her siblings, question for her prophylactic anticoagulation remains to be answered as most of the published literature suggests the use of anticoagulation in asymptomatic individuals to be reserved for periods of elevated risk of thrombosis (surgery/immobilization/pregnancy). ${ }^{8}$ She was also advised anti- $\beta 2 \mathrm{GP} 1$ antibodies as she was negative for $\mathrm{aCL}$ ( $\operatorname{lgG}$ and $\operatorname{lgM}$ ), so that decision for thromboprophylaxis could be justified.

In familial diseases, family members are vulnerable to the effects of psychological stress that is associated with repeated hospital visits and admissions, disruption in their daily commitments and work schedules, social and financial constraints and above all death of their loved ones. There is literature available regarding psychosocial problems in APS patients reported as high as $97 \% .9$ They include a wide spectrum of psychiatric issues like family dependence, memory loss, social losses, sexual limitations, depression, severe speech limitation, anxiety, learning difficulty, generalised phobia and suicide ideation. So far, no literature is available regarding the impact of the grave outcomes in asymptomatic members of APS families, as happened in Case 4. Early counselling and screening of family members who are at high risk of depression can reduce the psychiatric issues in the family members and save precious lives.

The occurrence of disease in families suggests some firm genetic association with the disease. But literature regarding genetic markers linked with APS shows inconclusive results. In a study by Goel et al., ${ }^{2}$ seven families were genetically analysed. They concluded that probable mode of inheritance of the culprit gene could be autosomal dominant. However, in all those families APS was not linked with HLA, beta 2 glycoprotein, anti thrombin III, Fas ligand, or IgK. In another study by Hirose et al., ${ }^{10}$ healthy controls from various races were studied and the results were compared with those from APS patients. The DNA segment containing position-247 polymorphism was investigated by polymerase chain reaction (PCR) and the polymorphism was detected by restriction endonuclease digestion. They concluded that in Asian APS patients, expression of a Valine at position 247 , is significantly linked with the presence of anti-beta $2 \mathrm{GPI}$ antibodies and, therefore, can be considered as a risk factor in this particular ethnic group. Further studies on identification of families with APS should provide insight into possibility of having genes/genetic factors that predispose APS individuals to the myriad clinical expressions of this syndrome. Genome-wide linkage studies are required for solving this mystery.

\section{PATIENTS' CONSENT:}

Consents were taken from all the patients.

\section{CONFLICT OF INTEREST:}

Authors declared no conflict of interest.

\section{AUTHORS' CONTRIBUTION:}

AS, SHK, MDK: Contributed equally to drafting and finalising the manuscript.

\section{REFERENCES}

1. Hoffbrand V, Higgs DR, Keeling DM, Mehta AB. Postgraduate hematology. Wiley-Blackwell $7^{\text {th }}$ Edition 2016:813-6.

2. Geol N, Oorrtel TI, Bali D, Anderson JP, Gourley I, Smith H, et al. Familial antiphospholipid antibody syndrome: Criteria for disease and evidence for autosomal dominant inheritance. Arthritis Rheum 1999; 42:318-27.

3. Duarte-García A, Pham MM, Crowson CS, Amin S, Moder KG, Pruthi RK, et al. Epidemiology of antiphospholipid syndrome: A population bases study. Arthritis Rheumatol 2019.

4. Islam MA, Wong KK, Sasongko TH, Gan SH, Wong JS. Familial primary antiphospholipid syndrome: A report of cooccurrence in three Malaysian family members. Eur $J$ Rheumatol 2016; 3:139-41. 
5. Mito T, Miura S, Takada K, Koyoshi R, Morii J, Sugihara M, et al. A case of coronary artery disease with antiphospholipid syndrome that showed repeated stent thrombosis. J Cardiol Cases 2011; 4:80-6.

6. Esen BA, Diz-Küçükkaya $R$, Inanç $M$. The significance and manage-ment of thrombocytopenia in antiphospholipid syndrome. Curr Rheumatol Rep 2015; 17:14.

7. Pengo V, Ruffatti A, Legnani C, Testa S, Fierro T, Marongiu F, et al. Incidence of first thromboembolic event in asymptomatic carriers of high risk antiphospholipid profile: A multicenter prospective study. Blood 2011; 118:4714-8.
8. Danowski A, Rego J, Kakehasi AM, Funke A, Carvalho JF, Lima IV, et al. Guidelines for the treatment of antiphospholipid syndrome. Rev Bras Reumatol 2013; 53:184-92.

9. Sadetski M, Tourinho Moretto ML, Correia de Araujo RP, de Carvalho JF. Frequency of psychosocial alterations in primary antiphospholipid syndrome: Preliminary study. Lupus 2018; 27: 837-40.

10. Hirose N, Williams R, Alberts AR, Furie RA, Chartash EK, Jain RI, et al. A role for the polymorphism at position 247 of the b2glycoprotein 1 gene in the generation of anti-b2-glycoprotein 1 antibodies in the antiphospholipid syndrome. Arthritis Rheum 1999; 42:1655-61. 